This copy is author's original pre-print version and may slightly differ from the official published version.

Full citation:

Kess, P., Belt, P., Harkonen, J., Anussornnitisarn, P. and Phusavat, K. (2009) 'Learning about design and development: the roles of industrial design and concurrent engineering', International Journal of Innovation and Learning, Vol. 6, No. 6, pp. 659-671.

DOI: https://doi.org/10.1504/IJIL.2009.02665

\title{
Learning on design and development: roles of industrial design and concurrent engineering
}

\author{
Pekka Kess, D. Tech. and D. Eng. (Pekka.Kess@oulu.fi) \\ Pekka Belt (pekka.belt@oulu.fi) \\ Janne Harkonen \\ Department of Industrial Engineering and Management \\ University of Oulu, PO BOX 4610, 90014 \\ Oulu, Finland
}

Pornthep Anussornnitisarn, Ph.D. (fengpta@ku.ac.th)*

Kongkiti Phusavat, Ph.D. (fengkkp@ku.ac.th)

Department of Industrial Engineering

Kasetsart University

Bangkok 10900, Thailand

*Corresponding author

\begin{abstract}
:
This research examines a design and development process for Small and Medium Enterprises (SMEs). The SMEs has to perform this process well for their business successes. The study tackles the confusions on the roles of Industrial Design (ID) within this process. These confusions potentially hinder SMEs's llong-term competitiveness. The study is part of the Concurrent Design in Networks (CODENET) project in Finland that focuses on improving ID in design and development. A total of six case companies from the Oulu region are observed and studied. The findings show that the confusions highlight various perceived roles of ID, a lack of interaction and two-way communication, external design sources, etc. In an attempt to address these problems, a practical framework, derived from the Concurrent Engineering (CE), is proposed jointly with case companies. This framework stresses the importance of working together across functional units within and outside a SME. It should be recognized that this framework is mainly for the business-to-business circumstance.
\end{abstract}

Keywords: industrial design; concurrent engineering; innovation, product design development 


\section{Introduction}

A success under intense international competitions requires design and development to be flexible, swift and cost effective. Unfortunately, there appears to be incremental improvement in this practice, especially for Small and Medium Enterprises or SMEs (Cooper, 1999; Moultrie et al., 2006). Moreover, given the trend in globalization and consumer preference, the timeliness has become increasingly important (El-Korany, 2007). In other words, a cycle time from an idea to a complete product (time-tomarket) needs to be as short as possible. Given this tremendous pressure from customers and competitors, a process relating to design and development has been scrutinized extensively. Many approaches and emerging concepts such as Configuration Management, Computer-aided Design, and Design for Life-cycle have been proposed to help design and development. They aim to help shorten a company's time to market (Swink et al., 1996). Elfving and Jackson (2003) further elaborated that "future success within industry demands stronger and more active cooperation between product and process development." Moreover, Liebowitz et al. (2007) argued that effective design and development as well as operational management could not rely on technology alone.

To highlight ongoing challenges in design and development (in addition to time, cost, and requirements), one must recognize the impacts from outsourcing and regulations (Phusavat el al., 2007). Furthermore, product specifications merely represent consumers' minimum expectation nowadays (Cagan and Vogel, 2002). An awareness of global competition and customers' psychology are also critical for design and development. In other words, a customer purchases products/ services that fulfill their complex needs. As a result, according to Cagan and Vogel (2002), the combination of style and technology using the right features was probably the best possible way to achieve customer satisfaction, and to maintain customer loyalty. Simply put, a successful product design and development must strike a balance among technical superiority, target costs, delivery requirements, laws and regulations, and appearance and look (Kano et al., 1984; and Zhang and von Dran, 2001).

Specifically for Industrial Design (ID), it is viewed as one of critical components for design and development (Ulrich and Eppinger, 2000). It successfully brings outward appearance, look, and feeling to new products. See Figure 1. According to Ulrich and Eppinger (2000), historically, design for pure functionalism was the norm. However, in the U.S, ID was somewhat different. While designers in Europe were mostly architects and engineers, the Americans essentially combined expertise and skills from various disciplines such as marketing, psychology, and engineering. For 
examples, European cars were simple and smooth, while the American cars had a lot of details and decorations that did not necessarily imply functional purposes. Finally, Blanchard (2004) indicated that design and development eventually needed to blend knowledge from different academic disciplines and to move beyond product's functionalities.

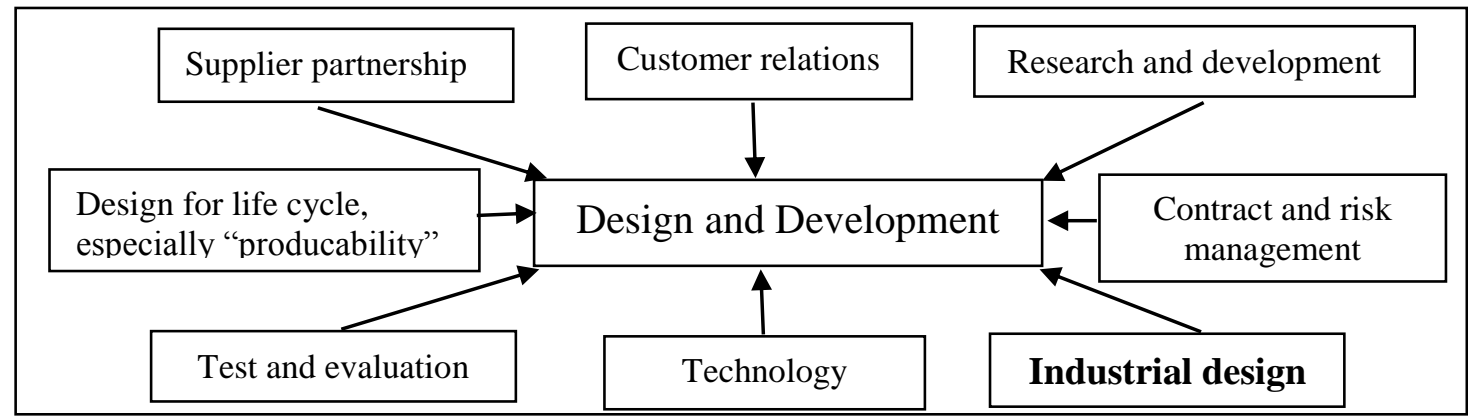

Figure 1: Components for Design and Development

(Adapted from Ulrich and Eppinger, 2000; and Blanchard, 2004)

Recently, product differentiation has become more crucial to customers (Verdú-Jover et al., 2008). ID's roles therefore become more complex. ID is now seen as a combined field where the arts, commerce and technology can strengthen the competitive position (Hertenstein et al., 2005; Gotzsch et al., 2006). Currently, technical and economic requirements, personality, and ergonomics have to be jointly considered (Gemser and Leenders, 2001; Govers and Schoormans, 2005; and Veryzer, 2005). Specifically, Hertenstein et al. (2005) and Moultrie et al. (2006) indicated that the ID success was closely related to financial performance and longterm profitability. To further highlight its importance, the budgets allocated to ID among European and American companies have been growing significantly (Gemser and Leenders, 2001; and Cooper et al., 2004). It is important to note that according to the Industrial Designers Society of America, ID can be defined as "the professional service of creating and developing concepts and specifications that optimize the function, value and appearance of products and systems for mutual benefit of both user and manufacturer."

To strengthen ID efforts within design and development, several suggestions have been emerged such as software applications (e.g., Inventor, SolidWorks, Pro/ENGINEER, CATIA, and NX or Unigraphics), intranet and internet communication, rapid prototyping, and simulation (Ulrich and Eppinger, 2000). On the other hand, there is an emerging concept addressing how a design project should be managed. This concept is called Concurrent Engineering (CE). It is important to note that other terms relevant to the CE include system engineering, simultaneous engineering, and integrated product-process development (Dean and Unal, 1992; Swink et al., 1996; Blanchard, 2004; Bowonder et al., 2004; and Webb et al., 2005).

Essentially, the CE calls for radical changes in a design and development process. It focused on an integration and communication among relevant parties to ensure producability, customer satisfaction, and life-cycle support (CETAM International, 2005). This approach is intended to cause the designers, from the outset, to consider all elements of the product life cycle from conception through disposal, including 
quality, cost, schedule and user requirements" (Blanchard, 2004). Elements commonly associated with the CE are as follows.

- System thinking, e.g. simultaneous development of products and processes (Bowonder and Sharma, 2004; and Webb et al., 2005)

- Organization of work into teams with the emphasis on communication and feedback (Carlson and Ter-Minassian., 1996; Prasad, 1996; Swink et al., 1996; Kauppinen, 1999; Carroll, 1998; and Elfving et al., 2003)

- Project management (Nihtila, 1999; and Webb et al., 2005)

- Quality Function Deployment (Swink et al., 1996; Kauppinen, 1999; and Dale, 2003)

- Continuous improvement (Carroll, 1998 ; Swink et al., 1999; and Webb et al., 2005)

- Technical design issues such as reliability, maintainability, life-cycle support and cost, usability, and environment (Blanchard, 2004; Webb et al., 2005)

- Managerial issues such as risk management, contract management, supplier management, customer-relation management (Kauppinen, 1999; Elfving et al., 2003; and Blanchard, 2004)

The benefits from the CE have included: (1) improved timeliness (Carter and Baker, 1992; Singh and Lewis, 1997; Carroll, 1998; Kauppinen, 1999; and Ahn et al., 1999), (2) fulfillment of product life-cycle requirements (Peters, 1989), (3) improved communication among functions and across several organizations such as customers and suppliers (Kauppinen, 1999), and (4) decreased development cost (Carroll, 1998; and Ahn et al., 1999). The mutual confidence and respect between functions and shared responsibilities are recognized as the CE's cornerstone.

\section{Problem background}

In the service-based economy (i.e., internet and information economies), SMEs constitute a substantial part of the country's wealth (Graham, 1999; Gunasekaran, 2000; and Van Stel et al., 2005). Several studies have indicated that these SMEs rely on speed and flexibility for their business excellence, including product/ service design and development (Acs, 1996; Beck and Demirguc-Kunt, 2006; Lee et al., 2007; and Mei, and Nie, 2008). Nevertheless, under different business circumstances (e.g., business-to-business, business-to-government, and business-to-customer), there appears to be some confusions of the ID practices for SMEs' design and development efforts in many countries (Manasserian, 2005). These confusions in the ID can negatively impact a company's long-term financial capability (Hertenstein et al., 2005).

In general, the SMEs' ID efforts have to adjust to the changes from both internal and external sources. Better communication and decisions during design and development are needed. More importantly, globalization and outsourcing trends have brought both new opportunities as well as strong competition from abroad (Melton et al., 2006). Nevertheless, Nixon (1999); European Commission (2000); Jarvinen and Koskinen (2001); Gemser and Leenders (2001); Hertenstein et al., (2005); and Govers and Schoormans, (2005) agreed that managing ID represented a new challenge in product design and development, and suggested more ID-based studies to be conducted. 
Specifically, according to a report by the Concurrent Design in Networks or CODENET, design and development efforts for SMEs will likely go through many changes in the near future. The pressure from customers on delivery, functionality, appearance, and cost will likely become more intense. The delicate balance between technical and non-technical issues during design and development is ever more critical. As a result, this CODENET project focuses on clarifying the roles of ID within a design and development process. Potential consequences facing SMEs from ineffective ID are a lack of new attractive products, a longer development time to markets, and an inability to fulfill customers' needs and requirements. See Figure 2.

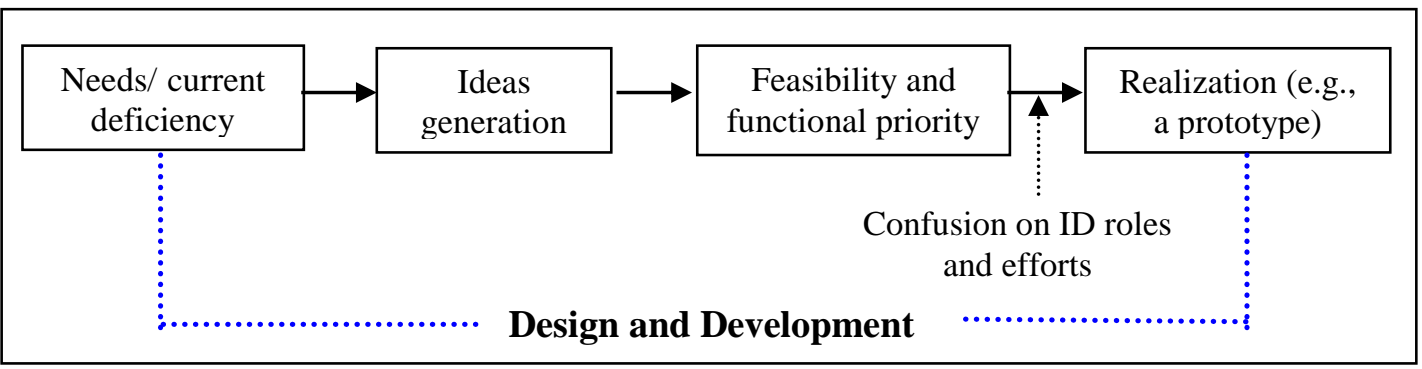

Figure 2: Problem Illustration

In this report, one of the key attribute to SMEs' design failures in Finland is that the viewpoint of ID is often based on a functional viewpoint (instead of an integrated perspective). Furthermore, there is apparently a lack of extensive understanding on how ID can be effectively utilized within a design and development process. These two premises are further supported by Wheelwright and Clark (1992), Gupta et al. (1996), Cooper (2001), Cagan and Vogel (2003), Blanchard (2004), Nyberg and Lindstrom (2005), and Subrahmanya (2005).

Based on the initial findings from the CODENET study's initial findings, many Finnish SMEs will continue to face fierce competition from abroad (especially Eastern Europe and Asia) and are in a serious need to strengthen their design and development efforts. Given their technological advancement (e.g., design software), accessibility to capitals, and staffs' competencies, the major concern is on how to better manage design and development-related activities. Therefore, a preliminary study is needed to identify current ID practices and ongoing obstacles facing SMEs with respect to their design and development efforts. This study is part of the CODENET project. It is partially funded by the Technology Development Centre of Finland, also known as TEKES. The primary aim from the CODENET-TEKES project is to outline current ID design practices among SMEs, and to develop a practical framework for participating SMEs on their ID deployment. In other words, the scope of this study is on the relationships of the ID and new product design and development efforts. It is important to note that this study involves mainly SMEs that operate in the business-to-business environment.

\section{Objectives}

The paper aims to provide insights of current ID practices within a design and development process. The expected benefits from this paper are to improve their design and development, and to reveal the possibility of the $\mathrm{CE}$ in advancing ID practices. 


\section{Methodology}

There are many steps to be taken in order to achieve the CODENET-TEKES project. These steps are as follows.

- Selection of case companies

- Data collection through observations and interviews

- Mapping out current design and development practices

- Identifying ID-related obstacles

- Together with case companies, proposing a modified ID framework with the $\mathrm{CE}$

- Discussion and verification

The case companies are SMEs operating in the Oulu region. Altogether, they are six SMEs participating in this research. These SMEs are considered as part of the hightech mechanics network. In general, they produce capital goods and are classified as an original equipment manufacturer (OEM). They operate almost exclusively in a business-to-business market. Their selection is based their business successes and excellent reputation with a rapidly-growing status. Due to their requests, their names and business background are to be kept confidential.

The data collection, based on the scope of the CODENET-TEKES project, focuses on the following three questions. What are the current product design and development practices? Other issues for the first question are the roles and current practices on ID, ongoing ID problems and their attributes or causes. The next question is that, based on the interviews and discussion, what should product design and development look like? Finally, the third question focus on the future roles of the ID for SMEs as they have to become more competitive and responsive to market demands. Other concerns within this third question include the following. How does ID fit into a proposed design model? Should the CE principles needed in SMEs' design and development of new/modified products?

\section{Results}

According to observations and interviews, product design and development are carried out differently among six case companies. As a result, there is no specific standard that can be uniformly mapped out. In addition, there is common awareness that design and development are unique and risky. Ongoing efforts in these companies to help manage this risk include participation, teamwork, knowledge sharing and transfer, communication, and use of external sources for specific expertise and skills. Furthermore, there is a consensus that design and development need to be improved, given expected intense competitions and customer demands in the near future. Ultimately, specific circumstances that hinder effective design and development are design work to be performed in a successive manner, a continuous use of external design resources, and a lack of communication across relevant parties.

From their opinions, the issues relating to supplier partnership, use of available technology, contract management are manageable. Their primary concern is the need to better integrate ID into design and development. It appears that the roles and potentials of ID are not well understood. For some participants, ID only deals with look and appearance. For some, ID addresses both technical and non-technical aspects of a design. Even in some cases, ID is viewed as a catalyst that helps communicate data and information across functional units within a company, 
suppliers, and customers. Due to this discrepancy, ID is perceived to be a major roadblock for effective design and development. The impacts from poorly-managed ID include delays, rework, cost overrun, and frequent miscommunications. Although ID is generally recognized as a challenge, a company must still fulfill customer requirements on product specifications, cost, and delivery. See Figure 3.

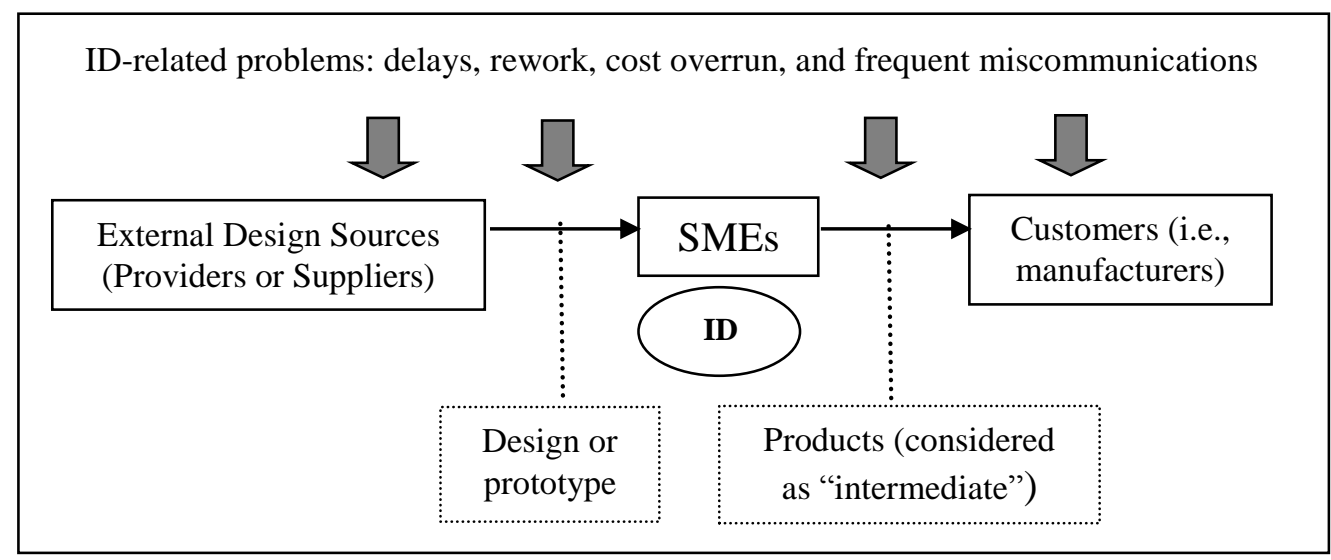

Figure 3: Findings from Case Companies on Design and Development

\section{Discussion}

To improve ID practices, its roles and scope need to be clarified. It is important to first reach the consensus on the ID among participating case companies. After a lengthy review, the ID should explicitly be an integral part of design and development. Furthermore, the ID should address both technical and non-technical aspects of a design. ID-related efforts should focus strongly on communication, data/ information sharing, and teamwork. Given this consensus, a framework that integrates the $\mathrm{CE}$ into the ID is developed. The underlying notion for this development is that this design and development framework is simple and flexible (for later becoming a custom-made model). Integrating the $\mathrm{CE}$ into the design process represents a more sensible way to strengthen ID for SMEs - in accordance with some opinions expressed by participants.

A proposed circular model that integrates the CE into the ID can be described as follows. The arrow patterns illustrate the commonly perceived requirements of teamwork, cooperation, knowledge sharing, communication, feedback, and interactions. For the proposed model, the core or center is a product to be design and developed. The key parameters for an optimal design include waste reduction in production, redundancy or design rework, timeliness, requirement fulfillments. Based on the interviews, it is generally typical that a design progresses through eight common phases. It is important to note that the level of intensity is expected to be different for individual SMEs. See Figure 4. 


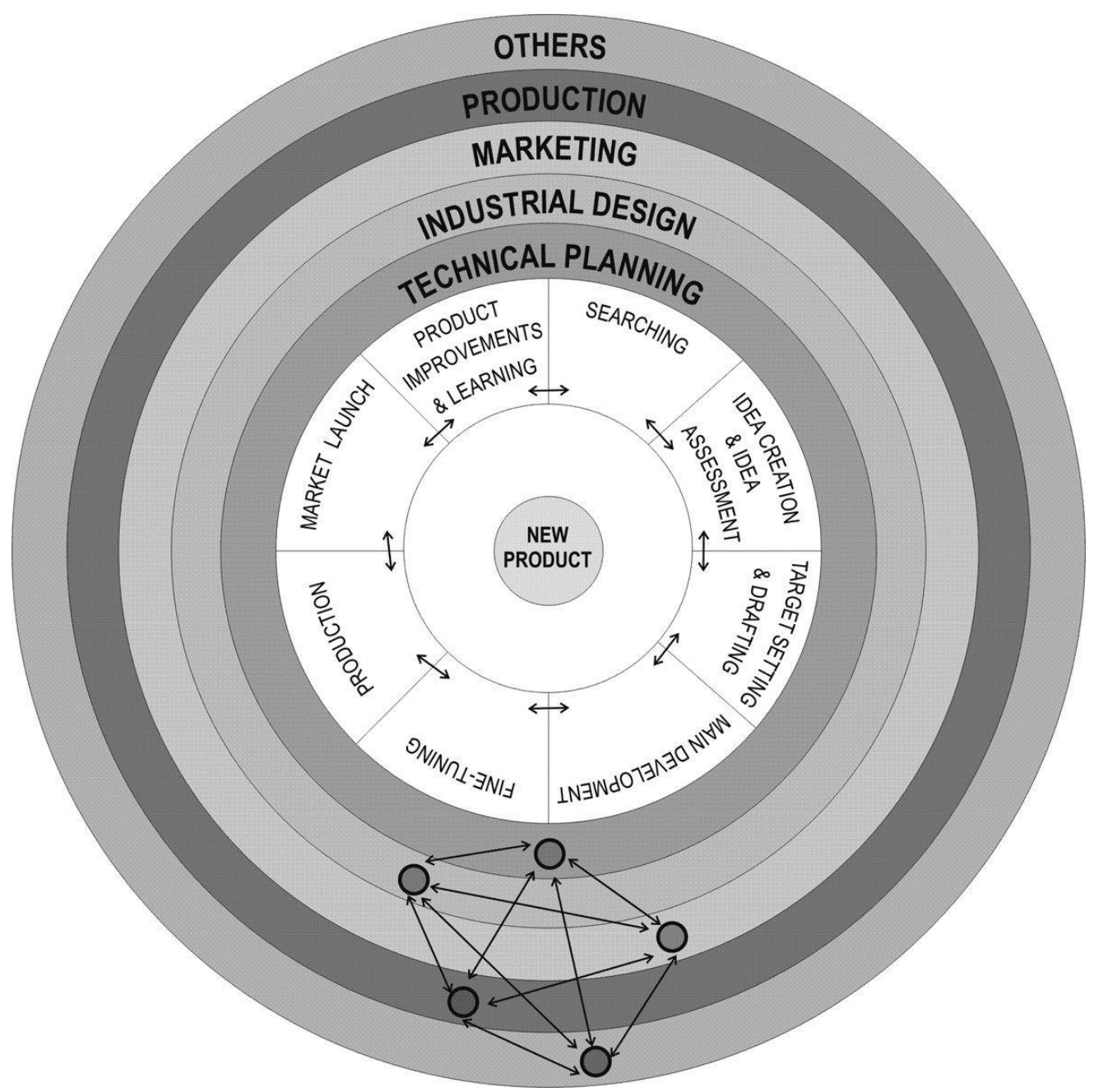

Figure 4: Proposed Design Model for SMEs

The eight common phases are: (1) searching/screening, (2) innovative idea creation and idea assessment, (3) requirement/ target setting and drafting, (4) main development, (5) fine-tuning, (6) production, (7) market launch and (8) product improvements and learning. These phases are evidently difficult to separate from one another and can be practiced in an overlapping fashion. The division into different phases can be regarded as a segment of a line over time. The overall goal of this proposed model is to help visualize relevant staffs within SMEs focus on design and development in a systematic manner. The ID is between technical and non-technical aspects of a design and is required to work together with production and others. The model's essential part is that design and development process efforts are not straightforward and cannot be viewed as a linear process. These efforts often go backwards after each phase. A full ring means, in practice, individuals in each segment is active as well as conduct data and information exchanges. It represents the underlying principle of the CE. It is also possible to stop or slow down at any phase. From time to time, there is a need to speed up or accelerate decisions. Nevertheless, it is undeniably a continuous process. As a result, a circular shape (rather than a linear structure) is used to highlight this nature as well as underlines the principles of monitoring and evaluation to ensure continuous improvement. 
The proposed model stresses the importance of working together among relevant stakeholders. Win-win attitude must prevail within a company and its providers and customers. By reducing unnecessary waste within a SME, a customer should be able to keep its competitive price. By reducing design rework from a provider, a SME can fulfill contractual obligations with its customers. To make the model more flexible, it is important to recognize that, for a small company, one person can perform multiple tasks relating design and development. The ring formation recognizes this flexibility. In addition, technical planning, production planning and the ID should be carried out simultaneously.

There are at least two ways to deploy the proposed model. This proposed model should be used as a baseline for planning and organizational preparation to help ensure successful design and development. The second way is to use the proposed model as a benchmark to help assess current practices and to identify areas for improvement. Another highlight from this proposed model includes a need to openly and continuously engage with external stakeholders ("others"), especially customers. Clearly, the model recognizes that discrete communications with customers are no longer enough. The model has received positive feedback from case companies. It is important to note that this model is probably more suitable for SMEs operating in the business-to-business environment.

Finally, the proposed model assists the viewpoint from companies' management that a design and development should be treated as a social process (Crabtree et al., 1993). Although the findings from this study are based on only six case companies, they should not be completely overlooked, especially for SMEs operating in the businessto-business environment. The future research should continue to focus on SMEs, especially those operating in different business environments such as business-toconsumer (Nihtila, 1999). The reason is that most research on design and development tend to focus very heavily on technological applications and large enterprises (Jarvinen and Koskinen, 2001; and Elfving and Jackson, 2003). Regardless of the size, product innovation (from design and development) plays a crucial role in business strategies and successes (Prajogo, 2007). The proposed framework aims to adapt the CE in order to better integrate the ID into design and development. It is jointly developed with participating case companies. It represents a baseline that can be further modified by other SMEs.

\section{Conclusion}

This research is part of the CODENET-TEKES project to improve SMEs' competitiveness through their design and development. The focus is on understanding the ID with respect to design and development, and providing improvement interventions. A total of six case companies from the Oulu region have participated in this study. They operate in the business-to-business environment. Apparently, the roles of ID are not well understood, especially when performing design and development in a successive manner and using external design sources. This improvement is based on the CE principles. The proposed model is then developed to address these problems. This development is performed jointly with participants from six case companies. Possible usages of this model are illustrated. Finally, the proposed model represents a baseline that is quite practical and can be easily modified to reflect SMEs' uniqueness. 


\section{References}

Acs, Z., Carlsson, B. and Karlsson C. (1999) The linkages among entrepreneurship, SMEs and macroeconomics. Cambridge University Press, Cambridge, UK

Ahn, S.; Roundy, S.; Wright, P.; and Liou, S. (1999) "Design consultant: a networkbased concurrent design environment" Proceedings of the ASME, International Mechanical Engineering Congress \& Exposition November 15-20, 1999, Nashville, Tennessee, pp. 563-569.

Beck, T. and Demirguc-Kunt, A. (2006) "Small and Medium-Size: Access to Finance as a Growth Constraint", Journal of Banking and Finance, Vol. 30, pp. 2931-2943.

Blanchard, B., (2004), System Engineering and Management, Wiley-Interscience: Singapore

Bowonder, B., Bhuyan, S. and Sharma K. (2004) "Multiple perspectives of concurrent engineering and their integration", International Journal of Manufacturing Technology and Management, Vol. 6, Nos. 3-4, pp. 372-390

Bowonder, B. and Sharma K. (2004) "Concurrent engineering: basis and implementation", International Journal of Manufacturing Technology and Management, Vol. 6, Nos. 3-4, p. 199- 213

Brown, K., Schmied, H. and Tarondeau, J. (2002) "Success factors in R\&D: a meta analysis of the empirical literature and derived implications for design management", Design Management Journal, Vol. 2, pp. 72-85.

Cagan, J. and Vogel, C. (2002) Creating breakthrough products: innovation from product planning to program approval. Prentice Hall:NJ

Carlson, S. and Ter-Minassian, N. (1996) Planning for Concurrent Engineering (Available at www.devicelink.com/mddi/archive/96/05/023, retrieved on 28 February 2006)

Carroll, B. (1998) "Manufacturing putting concurrency in concurrent product design teams", National Productivity Review, Vol. 17, No. 4, pp.17-22

Carter, D. and Baker, B. (1992) Concurrent Engineering: The Product Development Environment for the 1990s, Addison-Wesley: MA

CETEAM International (2005) What is Concurrent Engineering (CE)? (Available at www.ceteam.com/whatisceipdplm/whatisCE-IPD-PLM.asp, retrieved on 28 February 2006)

Cooper, R. (1999) "From experience: the invisible success factors in product innovation", Journal of Product Innovation Management, Vol. 16 No. 2, pp. 115-33

Cooper, R. (2001) Winning at New Products - Accelerating the Process from Idea to Launch, Perseus Publishing: the U.K 
Cooper, R., Wootton, A., Hands, D., Bruce, M. and Daly, L. (2004) Design Drivers: The role of designers in leading creativity and innovation in the supply chain, University of Art and Design Helsinki: Publication Series F27

Crabtree, R., Nirmal, B., and Fox, M. (1993) An analysis of coordination problems in design engineering (Available at www.eil.utoronto.ca/kbd/papers/crabtree-iced93.pdf, retrieved on 28 February 2006)

Dale, B. (2003) Managing Quality, Blackwell Publishing: NY

Dean, E. and Unal, R. (1992) Elements of Designing for Cost (Available at www.techreports.larc.nasa.gov/ltrs/PDF/aiaa-92-1057.pdf, retrieved on 28 February 2006)

El-Korany, A. (2007) "A knowledge management application in enterprises", International Journal of Management and Enterprise Development, Vol. 4, No. 6, pp. 693- 702

Elfving, S. and Jackson, M. (2003) Improving produceability of new products through concurrent engineering available www.idp.mdh.se/forskning/amnen/produktprocess/projekt/cooperation/publikationer/ CE2003.pdf, retrieved on 28 February 2006)

European Commission (2000) Report on the European Charter for Small Enterprises, Published by the Feira European Council for the June 19-20 Meeting

Gemser, G. and Leenders, M. (2001) "How integrating ID into the NPD process impacts on company performance", Journal of Product Innovation Management, Vol. 18 No. 1 , pp. 21-35

Gotzsch, J., Chanaron, J., and Birchall, D. (2006) "Product development with a focus on attractive product expression: an analysis of case studies", International Journal of Product Development, Vol. 3, Nos. 3/4, pp. 467-476

Govers, P. and Schoormans, J. (2005) "Product personality and its influence on consumer preference", Journal of Consumer Marketing, Vol. 22, No. 4, pp. 189-197

Graham, P. (1999) "Small business participation in the global economy", European Journal of Marketing, Vol. 33, Nos. 1/2, 1999, pp. 88-102

Gunasekaran, A. (2000) "World class manufacturing in small and medium enterprises", International Journal of Manufacturing Technology and Management, Vol. 2, No. 1, pp. $777-789$

Gupta, L., Chionglo, J. and Fox, M. (1996) A Constraint Based Model of Coordination in Concurrent Design Projects (Available at www.eil.utoronto.ca/kbd/papers/gupta-wetice96.pdf, retrieved on 28 February 2006) 
Hertenstein J., Platt, M., and Veryzer, R. (2005) "The impact of industrial design effectiveness on corporate financial performance", Journal of Product Innovation Management, Vol. 22, No. 1, pp. 3-21

Jarvinen, J. and Koskinen, I. (2001) Industrial Design as a culturally reflexive activity in manufacturing, the Finnish Innovation Fund (SITRA), Helsinki: Finland.

Kano, N., Seraku, N., Takahashi, F. and Tsuji, S. (1984) "Attractive and normal quality”, Journal of the Japanese Society for Quality Control, Vol. 14, No. 2, pp. 1126

Kauppinen, S. (1999) Development of technological competitiveness by integrating instruments and automation in process machinery (Available at www.herkules.oulu.fi/isbn9514252705, retrieved on 28 February 2006)

Lee, S., Lee, Z., and Lee, J. (2007) "Knowledge transfer in work practice: adoption and use of integrated information systems", Industrial Management \& Data Systems, Vol. 107, No. 4, pp. 501- 518

Liebowitz, J., Ayyavoo, N., Nguyen, H., Carran, D., and Simien, J. (2007) "Crossgenerational knowledge flows in edge organizations", Industrial Management \& Data Systems, Vol. 107, No. 8, pp. 1123- 1153

Manasserian, T. (2005) New realities in global markets and Thailand's economy today (Available at webh01.ua.ac.be/cas/PDF/CAS48.pdf, retrieved 2 April, 2007)

Mei, S. and Nie, M. (2008) "An empirical investigation into the impact of firm's capabilities on competitiveness and performance", International Journal of Management and Enterprise Development, Vol. 5, No. 5, pp. 574- 589

Melton, C., Chen, J., and Lin, B. (2006) "Organisational knowledge and learning: leveraging it to accelerate the creation of competitive advantages", International Journal of Innovation and Learning, Vol. 3, No. 3, pp. 254- 266

Moultrie, J., Clarkson, P., and Probert, D. (2006) "A tool to evaluate design performance in SMEs", International Journal of Productivity and Performance Management, Vol. 55, Nos. 3/4, pp.184-216

Nihtila, J. (1999) "R\&D - production integration in the early phases of new product development projects", Journal of Engineering and Technology Management, Vol. 16, No. 2, pp. 55-81

Nixon, B. (1999) "Evaluating design performance", International Journal of Technology Management, Vol. 17, Nos. 7-8, pp. $814-829$

Nyberg, M. and Lindstrom, M. (2005) The impact of design on economic performance Discussion Papers \# 982 by the Institute of the Finnish Economy

Peters, T. (1989) Creative Chaos, Gummerus Publishing: Finland 
Phusavat, K., Kanchana, R., and Helo, P. (2007) "Supplier management: past, present, and anticipated future perspectives", International Journal of Management and Enterprise Development, Vol. 4, No. 5, pp. 502-519

Prajogo, D. (2007) "The relationship between competitive strategies and product quality", Industrial Management and Data Systems, Vol. 107, No. 1, pp. 69- 83

Prasad, B. (1996) Concurrent Engineering Wheels (Available at www.eda.org/rassp/documents/newsletter/html/96q1/news_6.html, retrieved on 28 February 2006)

Rich, H. (2004) "Proving the practical power of design", Design Management Review, Vol. 15, No. 4, pp.29-34

Singh, K. and Lewis, J. (1997) "Concurrent engineering: institution, infrastructure and implementation”, International Journal of Technology Management, Vol. 14, No. 6, pp. $727-738$

Subrahmanya, M. (2005) "Small-scale industries in India in the globalization era: performance and prospects", International Journal of Management and Enterprise Development, Vol. 2 No. 1, pp. 122-139

Swink, M., Sandvig, J., and Mabert C. (1996) “Adding 'zip' to product development: concurrent engineering methods and tools", Business Horizons, Vol. 39, No. 2, pp. $41-49$

Ulrich, K. and Eppinger, S. (2000) Product design and development, McGraw-Hill: NY

Van Stel, A., Carree, M. and Thurik, R. (2005) "The effect on entrepreneurial activity on national economic growth", Small Business Economics, Vol. 24, No. 3, pp. 17-33

Verdú-Jover, A., Gómez-Gras, J., and Lloréns-Montes, F. (2008) "Exploring managerial flexibility: determinants and performance implications", Industrial Management \& Data Systems, Vol. 108, No. 1, pp. 70- 86

Veryzer R. (2005) "The Roles of Marketing and Industrial Design in Discontinuous New Product Development", Journal of Product Innovation Management, Vol. 22, No.1, pp. 21-30

Webb, C., Wunram, M., Lettice, F. and Klein, P. (2005) Improving Problem Solving Capabilities in Concurrent Engineering via Knowledge Transformation \& Six Complexity Science Principles available at www.public.cranfield.ac.uk/sims_staff/wccw1/Webb_Lettice_Wunram_Klein_ICE_2 005.pdf, retrieved on 28 February 2006)

Wheelwright, S. and Clark, K. (1992) Revolutionizing Product Development Free Press: NY 
Zhang, P. and von Dran G. (2001) "User expectations and rankings of quality factors in Different Web Site Domains", International Journal of Electronic Commerce, Vol. 6, No. 2, pp. 9-33 